\title{
Avaliação de risco a enchentes e inundações por krigagem ordinária em sistemas de informação geográfica
}

\section{Evaluation of a flood and flooding risk from kriging ordinary in geographical information systems}

Lucas Emanuel Servidoni. Geógrafo e Mestre em Ciências Ambientais, Instituto de Ciências da Natureza - UNIFAL, Brasil les.servidoni@gmail.com

Alexandre Elias de Miranda Teodoro Geógrafo e mestrando em Geografia pela Universidade Federal de Alfenas - MG, Brasil alexander_line@hotmail.com

Ronaldo Luiz Mincato Professor Associado II - Instituto de Ciências da Natureza - UNIFAL, Brasil ronaldo.mincato@unifal-mg.edu.br

Clibson Alves dos Santos Professor Associado I - Instituto de Ciências da Natureza - UNIFAL, Brasil clibsonsantos@gmail.com

\section{Resumo}

As enchentes e inundações são os desastres naturais que mais causam prejuízos sociais, econômicos e ambientais no Brasil. A avaliação e mapeamento de áreas de risco é feita por meio de metodologias quantitativas para modelar a paisagem e indicar os locais com maior probabilidade de ocorrência de desastres naturais. Este trabalho visou mapear processos hidrológicos extremos por meio da relação da densidade de drenagem com o índice de bifurcação com a ferramenta krigagem ordinária disponível no software ArcGIS 10.5. A partir do modelo digital de elevação foram geradas as cartas de declividade, hipsométrica e de drenagem para extrair as informações necessárias para realizar o cálculo. Posteriormente, foi inserido sobre a área de estudo uma grade regular para calcular tal parâmetro ao longo da bacia. Os pontos amostrados foram combinados por geoestatística resultando no mapa de risco natural a enchentes e inundações na bacia hidrográfica do Rio Machado. A metodologia apontou que a cidade de Poço Fundo está inserida em uma área propícia a processos hidrológicos violentos, contrariando a metodologia convencional da análise morfométrica que indicou que o Rio Machado não era propício a sofrer com enchentes e inundações.

Palavra-chave: Sensoriamento Remoto; Geomorfologia Ambiental; Geoestatística.

\begin{abstract}
Floods and floods are the natural disasters that cause the most social, economic and environmental damages in Brazil. The assessment and mapping of risk areas are done through quantitative methodologies to model the landscape and indicate the locations most likely to occur in natural disasters. This work aimed to map extreme hydrological processes through the relationship of drainage density to bifurcation index with the ordinary kriging tool available in ArcGIS 10.5 software. From the digital elevation model, the slope, hypsometric and drainage charts were generated to extract the necessary information to perform the calculation. Subsequently, a regular grid was inserted over the study area to calculate such parameter along the basin. The points sampled were combined by geostatistics resulting in a natural risk map to floods and floods in the Rio Machado basin. The methodology indicated that the city of Poço Fundo is located in an area
\end{abstract}


that is conducive to violent hydrological processes, contrary to the conventional methodology of morphometric analysis that indicated that the Machado River was not conducive to suffering from floods and floods.

Keywords: Remote Sensing; Environmental Geomorphology; Geostatistics.

\section{INTRODUÇÃO}

A quantidade e a intensidade de desastres naturais no Brasil estão aumentando nos últimos 10 anos (ALMEIDA et al., 2017). Seguindo a tendência mundial, é notável o crescimento no número de catástrofes naturais desde 1960. No ano de 2018 mais de 2.500 pessoas morreram no Brasil e mais de 500 famílias ficaram desalojadas devido ao descaso das autoridades (GONÇALVES SANTOS; VENTORINI, 2018). Os desastres naturais são causados por fenômenos da dinâmica externa e interna da Terra. Os principais eventos no Brasil são: enchentes e inundações, escorregamentos de solo e/ou rochas e tempestades, em geral, associados a episódios climáticos extremos, tais como, chuvas prolongadas e intensas em períodos curtos, que ocorrem em geral no verão nas regiões Sul e Sudeste e no inverno na região Nordeste (ALMEIDA et al., 2017).

Enchente corresponde à elevação temporária do nível de água em um canal de drenagem desencadeado geralmente por precipitações prolongadas. As inundações são caracterizadas pelo extravasamento do canal de drenagem para áreas marginais, ocupando o leito maior. A impermeabilização de bacias hidrográficas no perímetro urbano aliado aos altos índices de pluviosidade do verão eleva o escoamento superficial das águas pluviais, aumentando o nível de rios e desencadeando processos hidrológicos extremos (TAOFIK et al., 2017).

A análise de parâmetros morfométricos de bacias hidrográficas é feita pela interpretação de informações da rede de drenagem e do relevo (MEDHI et al., 2017). Segundo Medhi et al. (2017), a análise morfométrica de bacias hidrográficas consiste em quantificar a distribuição dos elementos superficiais que caracterizam o relevo e a rede de drenagem. Esta análise foi introduzida no estudo geomorfológico para compreender a configuração e a evolução dos parâmetros hidrológicos de bacias hidrográficas.

Dos parâmetros da rede de drenagem e do relevo, Santos e Sobreira (2008) identificaram as potencialidades e fragilidades ambientais em bacias afluentes do Alto Rio das Velhas, no Quadrilátero Ferrífero, Minas Gerais. Assim, foi possível contribuir com sugestões para a tomada de decisão sobre o uso e ocupação do solo, além de fomentar projetos de recuperação e preservação ambiental.

A importância da análise morfométrica para avaliar parâmetros físicos de bacias hidrográficas é discutida por Christofoletti (1999). Segundo o autor, tais parâmetros podem revelar indicadores específicos para um determinado local, tornando possível quantificar e qualificar a 
vulnerabilidade ambiental em bacias hidrográficas. Atualmente, esta análise é realizada em ambiente de Sistemas de Informação Geográfica (SIG) e tem sido eficiente (SANTOS; BACCARO, 2014; SALIH, 2012; MEDHI et al., 2017; TAOFIK et al., 2017).

A análise morfométrica é feita a partir de índices geométricos definidos por modelos digitais de elevação (MDE). Os MDE são estruturados em grades retangulares, onde, cada pixel tem um valor numérico associado à elevação correspondente. Os MDE são estruturados a partir de grades retangulares ou triângulos vetoriais (KIRAN KUMAR et al., 2018). O MDE utilizado nesta pesquisa foi gerado a partir de radares interferométricos do Shuttle Radar Topography Mission (SRTM). Os dados altimétricos do SRTM são disponibilizados originalmente pela National Aeronautics and Space Administration com resolução espacial de $30 \mathrm{~m}$ (VALERIANO et al., 2006).

Saud (2009) aplica a análise morfométrica para avaliação da rede de drenagem e do relevo na Península Arábica, uma região de clima árido, baixas precipitações e elevado fluxo de material sedimentar. A Geologia local é constituída por rochas ígneas intrusivas e sedimentares. Saud (2009) a princípio corrigiu a rede de drenagem com a ferramenta Fill do SIG ArcGIS 10.5 (ESRI, 2015). Esta ferramenta avalia o comportamento de pixels do MDE e por um filtro retira os dados incoerentes. Essa correção foi necessária devido ao grande fluxo de material sedimentar que dificulta a delimitação automática da rede de drenagem.

Os índices utilizados por Saud (2009) foram: densidade de drenagem, frequência de drenagem, sinuosidade do canal de drenagem, hierarquia de drenagem, relação de bifurcação, densidade do fluxo de junção, fluxo de direção dominante e a Relação da Densidade de Drenagem com o índice de Bifurcação (RDdRb). Saud (2009) conclui que RDdRb é um instrumento para avaliar áreas sujeitas a processos de inundações e formação de zonas de aquífero. Dessa forma, o parâmetro citado é estimador de cheias em canais de drenagem e o nível de recarga potencial de águas subterrâneas. Além disto, a RDdRb é indicador da capacidade de infiltração de bacias hidrográficas.

A análise morfométrica é essencial no processo de gerenciamento de recursos hídricos. Saud (2009) orienta que a análise morfométrica é pré-requisito para qualquer ação que interfira na rede de drenagem e no relevo. Por se tratar de um método quantitativo de modelagem hidrológica, a análise morfométrica é amplamente utilizada para compreender e caracterizar o comportamento hidrológico, fundamental para atenuar os desequilíbrios da ocupação humana desordenada.

Considerando a compartimentação topográfica, a declividade, a altimetria e posterior correlação destes produtos com a análise morfométrica, Altin (2010) buscou compreender a dinâmica dos processos erosivos no local de trabalho. Concluiu que, regiões com altas declividades, diferenças altimétricas acentuadas e com material resistente à erosão são naturalmente vulneráveis a 
processos de inundação. Isso ocorre porque regiões com baixas taxas de infiltração tendem a acumular água nas camadas superficiais do solo o que satura rapidamente o nível freático, causando processos hidrológicos extremos (ALTIN, 2010).

Avaliando parâmetros da morfométricos de bacias hidrográficas utilizando técnicas estatísticas, Purohit e Parmar (2017) constataram que existe uma relação significativa entre os efeitos da inclinação do relevo e os aspectos morfométricos. Purohit e Parmar (2017) apresentam uma proposta de análise morfométrica baseada em análises estatísticas e obtiveram resultados satisfatórios. Constataram que bacias hidrográficas localizadas sobre as encostas íngremes são altamente dissecadas e formadas por materiais mais grosseiros. Isto é importante, pois, permite avaliar tais características em campo, dando sustentação para os resultados estatísticos obtidos no trabalho (PUROHIT; PARMAR, 2017).

A partir da década de 80, a geoestatística passou a ter ampla aplicação em diversas áreas do conhecimento, tais como: Agricultura de Precisão, Análise Espacial de Crimes, Cartografia, Climatologia, Ecologia da Paisagem, Engenharia Florestal, Epidemiologia, Geologia Ambiental, Geologia do Petróleo, Geotecnia, Hidrogeologia e Pedologia. Com a expansão crescente do método Geoestatístico, praticamente todos os softwares para confecção de mapas ou SIG agregaram módulos para este tipo de trabalho (YAMAMOTO; LANDIM, 2013).

O melhor estimador de uma variável regionalizada, segundo Yamamoto e Landin (2013), deve considerar as respectivas posições relativas, ou seja, compreender as características estruturais do fenômeno. Qualquer variável dependente do espaço, além do caráter aleatório, apresenta um caráter estrutural que pode ser tratado como variável regionalizada, e, portanto, segundo Yamamoto e Landim (2013) abordada pelo formalismo desenvolvido pela geoestatística. Ainda segundo Yamamoto e Landim (2013), o termo geoestatística tem uma abrangência mais ampla do que a dada originalmente por seu fundador, e pode ser definido como uma subárea da Estatística que estuda variáveis regionalizadas.

A krigagem é o processo geoestatístico de estimativa de valores de variáveis distribuídas no espaço e/ou tempo, com base nos valores vizinhos quando considerados interdependentes pela análise. A krigagem ordinária pode ser comparada com os métodos tradicionais de estimativa por médias ponderadas ou por médias móveis, mas a diferença fundamental é que somente a krigagem apresenta estimativas não tendenciosas e mínima variância associada ao valor estimado (YAMAMOTO; LANDIM, 2013).

As estimativas geoestatísticas são superiores aos demais métodos de interpolação numérica. Segundo Yamamoto e Landim (2013), isto ocorre porque fazem uso da função variograma, que é uma função da distância entre pontos, mas depende da existência ou não do efeito pepita, da amplitude e da presença de anisotropia. A estimativa geoestatística tem por objetivo a 
modelagem de fenômenos espaciais, ou seja, determinar a distribuição e variabilidade espacial de uma variável de interesse.

A krikagem é baseada no variograma, que permite representar quantitativamente a variação espacial de um fenômeno. A função variograma mede a variância entre pontos separados por uma distância, dessa forma, amostras próximas são mais parecidas entre si, consequentemente, a variância é menor. Conforme a distância aumenta os valores das amostras ficam mais diferentes e aumenta a variância (YAMAMOTO; LANDIM, 2013).

Com o avanço e popularização dos SIG, as análises espaciais se tornaram mais rápidas, menos custosas e mais eficientes. A partir de ferramentas quantitativas, a distribuição de informações geográficas se torna mais segura e, consequentemente, mais vantajosa, sendo bastante utilizada em diversas instituições de pesquisa e ensino, bem como pela iniciativa privada e pelo poder público.

A análise e o mapeamento de áreas de risco podem contribuir com o poder público na elaboração de medidas preventivas emergenciais para contenção e/ou amenização dos prejuízos sociais, econômicos e ambientais derivados de desastres naturais. Assim, o presente trabalho propôs avaliar as potencialidades e fragilidades ambientais da rede hidrográfica e do relevo da bacia hidrográfica do Rio Machado, sul de Minas Gerais a partir de análise morfométrica e geoestatística aplicada.

A krigagem, neste estudo, busca distribuir geograficamente o comportamento do RDdRb na bacia hidrográfica do Rio Machado. O RDdRb foi escolhido pois é indicativo do grau de vulnerabilidade natural de bacias hidrográficas a sofrerem os processos hidrológicos de enchentes e inundações. Portanto, o conhecimento prévio do seu comportamento pode ajudar a estabelecer ocupações planejadas em bacias hidrográficas, reduzindo a exposição da população aos riscos associados às enchentes (SAUD, 2009).

\section{MATERIAIS E MÉTODOS}

A área de estudo compreende a Bacia Hidrográfica do Rio Machado, sul de Minas Gerais, Brasil, e abrange $1000 \mathrm{~km}^{2}$ dos Municípios de Alfenas, Campestre, Congonhal, Espírito Santo do Dourado, Ipuiúna, Machado, Paraguaçu e Poço Fundo. A Figura 1 ilustra a localização da bacia hidrográfica cujos usos da terra principais são: pastagem, urbano, mata nativa e agricultura. O Rio Machado é um canal de $6^{\circ}$ ordem na escala de 1:250.000.

$\mathrm{O}$ arcabouço geológico é composto majoritariamente por granitos muito resistentes à erosão, com afloramentos rochosos no alto curso do rio Machado e nas elevadas declividades. Devido às baixas permeabilidades e alta resistência a erosão e aos solos pouco profundos e às 
elevadas declividades ocorre o escoamento subsuperficial colaborando para a saturação do lençol freático. Isto, aliado a eventos pluviométricos intensos e prolongados intensifica enchentes e inundações.

Os solos mais representativos da bacia hidrográfica são os Latossolos Vermelho distróficos em áreas de relevo suave e suave ondulado ( 0 a $8 \%$ de declividade), Cambissolos e Neossolos Litólicos em áreas de relevo ondulado e forte ondulado (8 a 20\% de declividade), nas áreas de divisor de águas e no alto curso do rio Machado. Os Latossolos são bem drenados e profundos e é o mais representativo de regiões tropicais. Os cambissolos e Neossolos são solos jovens pouco profundos, com nítido contato do solo com a rocha parental. São solos frágeis associados a áreas de elevada declividade e, portanto, considerados inapropriados para a utilização agrícola e construções civis sem as devidas precauções geotécnicas. Por se tratar de solos rasos, a saturação do lençol freático ocorre de forma rápida e favorece o escoamento subsuperficial e os deslizamentos de massa (SERVIDONI et al., 2016).

A geomorfologia da área é variada, possuindo relevos forte ondulados e escarpados nas bordas e no alto curso da bacia do Rio Machado associados a formações graníticas. No médio curso do Rio Machado existe a presença de um relevo montanhoso derivado de uma falha geológica, que direciona a drenagem do alto curso para uma única confluência, formando um Canion. Logo abaixo, está localizado o Município de Poço Fundo, que recebe uma grande descarga de água em períodos de chuvas intensas, devido a relevos íngremes (Figura 1). Próximo à foz, o relevo é caracterizado como suave ondulado e plano. A rede de drenagem é classificada como dentrítica e fortemente influenciada pelo relevo. Foram contabilizados 682 canais de drenagem com um comprimento total de $797549 \mathrm{~m}$. A densidade de drenagem calculada foi de $7,84 \mathrm{~m} \cdot \mathrm{m}^{-2}$, sendo classificada como alta.

Foi utilizado uma imagem ETM+/LANDSAT 7 com composição colorida R5G4B3, órbita/ponto 219/075, obtidas em 26/08/2018 para confeccionar o mapa de localização da área de estudo e análise exploratória do uso da terra. O Município de Machado (Figura 1) fica à jusante da rede de drenagem, enquanto Poço Fundo há área de convergência dos canais de drenagem do Rio Machado (Figura 1).

As imagens utilizadas do SRTM foram a SF-23-V-D e SF-23-Y-B mosaicadas no software ArcGIS 10.5 disponibilizado no Laboratório de Geologia e Paleontologia da Universidade Federal de Alfenas (ESRI, 2015). As imagens do SRTM foram indispensáveis para calcular o valor da densidade de drenagem e o Índice de Bifurcação, tal como a relação entre eles.

Os mapas altimétricos, de declividade e hidrográfico foram gerados a partir do MDE. Em vários pontos do MDE ocorrem imperfeições ou informações incoerentes com a realidade. Como solução, foi utilizado a extensão DEM Surface Tools do ArcGIS 10.5, preenchendo os valores inexistentes de pixels pela média dos pixels adjacentes (ESRI, 2015). 
Para extração da rede de drenagem foi utilizado o aplicativo Hidrology do ArcGIS 10.5, a partir dos seguintes passos: geração do arquivo Fill, Flow Direction, Flow Accumulation, Con, Stream to Feature, Wathershed (ESRI, 2015).

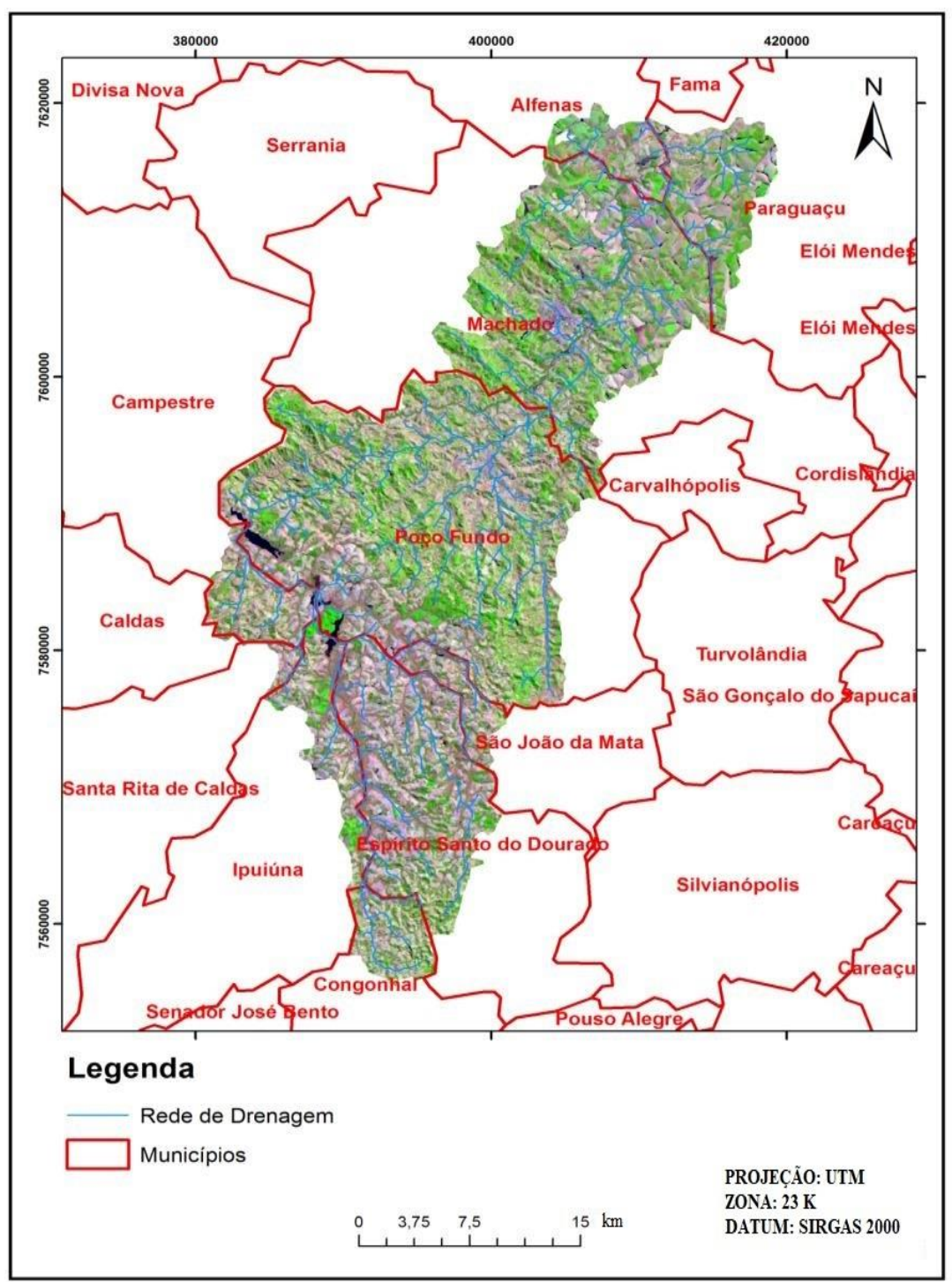

Figura 1 - Bacia Hidrográfica do Rio Machado, sul de Minas Gerais - Brasil. Fonte - Organização dos autores.

A ferramenta Flow Direction, avalia a propriedade natural da água em escoar pelo caminho mais fácil. Dessa forma, o algoritmo faz uma varredura sobre o MDE identificando os fundos de vales e de talvegues. Pela ferramenta Flow Direction, as áreas mais prováveis para o escoamento da água são mapeadas e utilizadas na ferramenta Flow Accumulation.

Flow Accumulation é um algoritmo que localiza as áreas mais prováveis para acúmulo de água. Essa informação é essencial, pois após a geração dos arquivos Flow Accumulation e Flow Direction, a ferramenta Stream to Features une os pontos de acumulação da água com as áreas mais prováveis de escoamento, delimitando, desta forma, os canais de drenagem. 
A amostragem foi realizada pelo Hawths Tools no ArcGIS 10.5 e permitiu o tratamento estatístico do RDdRB. Então foi criada uma malha regular que subdividiu a bacia hidrográfica em polígonos com $7 \mathrm{~km}^{2}$ (ESRI, 2015).

A grade foi inserida sobre o MDE para realizar o cálculo para o RDdRb para 52 amostras. Cada polígono onde foi calculado o RDdRb é transformado em um ponto com o valor correspondente ao índice. Esse procedimento é necessário para uso da ferramenta krigagem ordinária no ArcGIS 10.5 (ESRI, 2015). As amostradas foram selecionadas de forma aleatória, abrangendo áreas com e sem a presença de recursos hídricos.

A RDdRb é expressa pela fórmula:

$$
\mathrm{RDdRb}=\frac{L t / A}{N w / A w+1}
$$

Em que:

$\mathrm{Lt}=$ comprimento total de canais de drenagem;

$\mathrm{A}=$ área da bacia;

$\mathrm{Nw}=$ número total de canais de qualquer ordem;

$\mathrm{Nw}+1=$ número total de canais de ordem imediatamente superior.

A RDdRb pode ser utilizada como indicativo da vulnerabilidade natural de uma bacia hidrográfica a processos de enchentes e inundações e de potencialidade em recarga de aquíferos. A Krigagem Ordinária foi aplicada para mensurar a distribuição espacial da RDdRb. Seu produto final é um índice que varia de 0 a 1 , sendo que, quanto mais próximo de 1 , maior a vulnerabilidade natural da área a processos hidrológicos extremos.

Os valores obtidos da RDdRb foram inseridos na ferramenta krigagem ordinária pelo ArcGIS 10.1 na extensão Statical Analysis Tools. Os produtos desta aplicação foram: o histograma dos dados, gráfico da distribuição normal (QQ), mapa voronoi, análise de tendências e o semivariograma (ESRI, 2015).

O histograma fornece uma descrição contínua dos dados. Apresenta a distribuição de frequência para os dados da RDdRb e calcula o resumo da estatística básica do conjunto de dados. A frequência dos dados dentro de cada classe é representada pelas barras. Em geral, as características importantes de uma distribuição estão relacionadas ao valor central, a propagação e a simetria. Para uma verificação rápida, se a média e mediana tem valores aproximados, pode indicar que os dados apresentam distribuição próxima da normal (YAMAMOTO; LANDIN, 2013).

O Gráfico QQ é usado para comparar a distribuição de dados para um padrão normal. Quanto mais próximos estiverem os pontos da linha de tendência normal $\left(45^{\circ}\right)$, melhor será a 
distribuição dos valores amostrais. A interface QQ é um gráfico em que as duas distribuições de quartis são representados em função um do outro. Para duas distribuições idênticas, o gráfico QQ será uma linha reta (OLIVEIRA et al., 2018).

Cada haste vertical no gráfico de tendência, representa a localização e o valor (altura) do RDdRb. Os pontos são projetados sobre planos perpendiculares, leste-oeste e norte-sul. O polinômio que melhor se ajusta é interpolado através dos pontos projetados, indicando as tendências em direções específicas. Se a linha tem um aspecto plano, isto indicaria que não há qualquer tendência (OLIVEIRA et al., 2018).

Os produtos listados avaliam a qualidade dos dados amostrados para eventuais transformações. Assim, os dados foram inseridos sem qualquer transformação prévia como sugerido por Yamamoto e Landim (2013) para krigagem ordinária.

Yamamoto e Landim (2013) discutem que o Semivariograma possui maior acurácia para distribuição de índices cálculados sobre a superfície terrestre. O semivariograma permite que você examine a autocorrelação espacial entre os pontos de amostras medidas. É acreditado que os dados mais próximos são mais parecidos do que os mais distantes. O semivariograma examina esta relação. Para tanto, um valor de semivariância, é representado no eixo y em relação à distância que separa cada par de medições, representada no eixo x (YAMAMOTO; LANDIN, 2013).

Como as amostras são espaçadas irregularmente na bacia é necessário estabelecer limites de tolerância para direção do vetor e distância entre os pontos do dispositivo de pesquisa da ferramenta krigagem (Lag). Tal ferramenta foi dividida em quatro setores com ângulos de $45^{\circ}$, com tolerância angular de $13^{\circ}$. O Lag utilizado para a direção foi de $1.240 \mathrm{~m}$. Ao todo a área foi avaliada por 12 dispositivos de pesquisa. A ferramenta Geoanalisys Tools do ArcGIS 10.5 foi usada para o cálculo do semivariograma. Os valores foram definidos considerando a distância média entre um ponto e outro na bacia hidrográfica (ESRI, 2015).

\section{RESULTADOS E DISCUSSÃO}

Os valores de RDdRb ilustrados na Tabela 1 relaciona dois índices importantes da Análise Morfométrica: A densidade de drenagem e o índice de bifurcação. A densidade de drenagem expressa o potencial de bacias hidrográficas em gerar novos cursos d’água. A capacidade de gerar novos cursos de água é uma informação estratégica na compreensão da vulnerabilidade de bacias de drenagem a enchentes e inundações durante períodos chuvosos. Quanto maior a densidade de drenagem maior a capacidade da bacia em gerar rios temporários. Quanto mais canais de drenagem são gerados em períodos chuvosos aliados a altas declividades e a solos rasos, maior a 
probabilidade de saturação do lençol freático e, consequentemente, maior chance de enchentes e inundações (LI et al., 2018).

O índice de bifurcação ou relação de bifurcação é indicativo das formas de relevo predominantes em bacias hidrográficas. Valores elevados do índice de bifurcação indicam áreas montanhosas onde a Morfogênese é maior que a Pedogênese, indicando que o relevo está em pleno processo erosivo. Valores elevados da relação de bifurcação indicam áreas com solos rasos, devido à alta declividade da bacia junto ao arcabouço geológico resistente ao intemperismo. Essas duas variáveis foram constatadas com o MDE, carta geológica na escala 1:100.000 e em verificações de campo.

Tabela 1 - Valores da Relação da Densidade de Drenagem com o Índice de Bifurcação para Amostras Internas e Externas da Bacia Hidrográfica do Rio Machado.

\begin{tabular}{cccccccc}
\hline Amostras & Valores & Amostras & Valores & Amostras & Valores & Amostras & Valores \\
\hline A 01 & 0,05 & A 14 & 0,12 & A 27 & 0,11 & A 40 & 0,09 \\
A 02 & 0,11 & A 15 & 0,14 & A 28 & 0,11 & A 41 & 0,05 \\
A 03 & 0,07 & A 16 & 0,12 & A 29 & 0,16 & A 42 & 0,17 \\
A 04 & 0,13 & A 17 & 0,10 & A 30 & 0,18 & A 43 & 0,003 \\
A 05 & 0,14 & A 18 & 0,12 & A 31 & 0,18 & A 44 & 0,24 \\
A 06 & 0,16 & A 19 & 0,18 & A 32 & 0,14 & A 45 & 0,15 \\
A 07 & 0,08 & A 20 & 0,20 & A 33 & 0,22 & A 46 & 0,13 \\
A 08 & 0,12 & A 21 & 0,15 & A 34 & 0,21 & A 47 & 0,2 \\
A 09 & 0,15 & A 22 & 0,05 & A 35 & 0,14 & A 48 & 0,09 \\
A 10 & 0,10 & A 23 & 0,19 & A 36 & 0,27 & A 49 & 0,25 \\
A 11 & 0,17 & A 24 & 0,16 & A 37 & 0,03 & A 50 & 0,11 \\
A 12 & 0,21 & A 25 & 0,04 & A 38 & 0,15 & A 51 & 0,12 \\
A 13 & 0,28 & A 26 & 0,02 & A 39 & 0,01 & A 52 & 0,02 \\
\hline
\end{tabular}

Fonte - Organização dos autores. A: amostra.

A correlação entre a capacidade de gerar novos cursos de água e o tipo de revelo dominante na bacia hidrográfica é possível avaliar a vulnerabilidade natural a enchentes e inundações. Quando a RDdRb é espacializada na bacia hidrográfica do rio Machado é obtida a localização das áreas mais vulneráveis a sofrerem processos hidrológicos extremos. O uso da krigagem ordinária para distribuir a $\mathrm{RDdRb}$ permitiu mensurar áreas não amostradas na Bacia Hidrográfica, generalizando os dados com intervalo de confiança de 95\% (YAMAMOTO; LANDIM, 2013).

A Tabela 2 ilustra os valores de parâmetros morfométricos calculados da Bacia Hidrográfica do Rio Machado. Segundo os parâmetros foi possível medir algumas características. 
Tabela 2 - Valores de Parâmetros Morfométricos da Bacia Hidrográfica do Rio Machado cálculados na Bacia como Unidade Funcional.

\begin{tabular}{|c|c|c|c|}
\hline Parâmetro Morfométrico & Valores & Parâmetro Morfométrico & Valores \\
\hline Área $\left(\mathrm{km}^{2}\right)$ & 1.000 & Índice de Rugosidade & 4,500 \\
\hline Densidade de Drenagem $\left(\mathrm{km} \cdot \mathrm{km}^{-2}\right)$ & 1,000 & Índice de Bifurcação & 4,500 \\
\hline 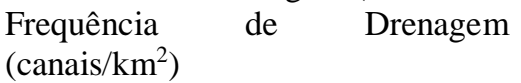 & 2,420 & Índice de Forma & 6,000 \\
\hline Amplitude Altimétrica (m) & 711 & Relação de Relevo & 0,007 \\
\hline $\begin{array}{l}\text { Relação do Índice de Bifurcação e } \\
\text { Densidade de Drenagem }\end{array}$ & 0,220 & & \\
\hline
\end{tabular}

Fonte - Organização dos autores.

- Valores acima de 2,00 do Índice de Rugosidade indicam que o relevo está em fase de dissecação inicial. Logo, a declividade média da bacia é alta e o relevo possui características predominantemente montanhosas.

- Valores acima de 0,200 para o Índice de Bifurcação indicam que a Bacia é linear e montanhosa, com declividades elevadas e, consequentemente, solos rasos devido ao material geológico resistente ao intemperismo.

- O Índice de Forma é indicativo de que a Bacia Hidrográfica é alongada. Bacias alongadas e com declividades altas fazem com que a vazão dos cursos d'água sejam mais elevadas do que em bacias circulares e com baixas declividades.

A Figura 2 apresenta a espacialização da RDdRb e a distribuição dos municípios inseridos da área. A RDdRb foi organizada em dez classes, possuindo coloração entre o verde, amarelo e vermelho. As classes com coloração verde indicam áreas com baixa probabilidade de enchentes e inundações e estão inseridas em locais com ausência de canais de drenagem. A coloração amarela indica áreas com média probabilidade de ocorrência de enchentes e inundações. São áreas com presença de canais de drenagem, porém não é áreas com desembocadura de canais oriundos de subbacias hidrográficas, o que diminui a probabilidade de ocorrência de enchentes e inundações.

Foi verificado que a porção mais vulnerável da bacia hidrográfica se encontra sobre o Município de Poço Fundo (Figura 2), que segundo o inventário de ocorrência de desastres naturais obtidos na Prefeitura do município possui histórico recorrente de enchentes e inundações. A região do município de Machado possui um valor médio para RDdRb coerente com o histórico de enchentes e inundações deste Município segundo o inventário de ocorrências disponibilizado pela prefeitura de Machado. 


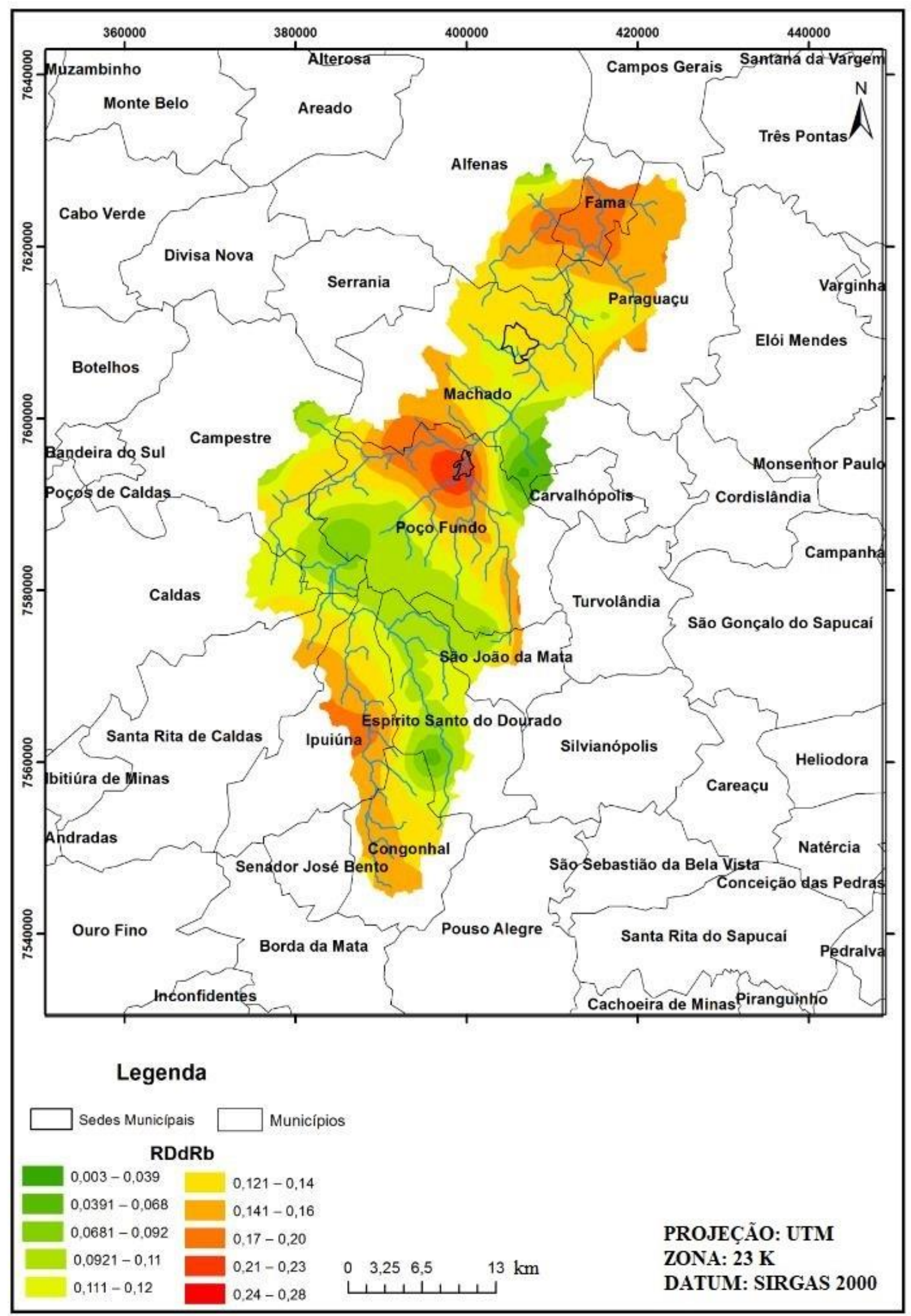

Figura 2 - Modelo krigado para a Relação da Densidade de Drenagem com o Índice de Bifurcação (RDdRb). Fonte - Organização dos autores. 
A correlação do modelo krigado a análise morfométrica do rio Machado (LIMA, 2010) permitiu identificar que o valor elevado da RDdRb está associado ao desnível do curso principal do Rio Machado (Figura 3A) que ocorre nesta área, próximo a Poço fundo (Figura 2). Esta correlação evidência que o desnível do Rio Machado, aliado às baixas declividades e altitudes (Figura 3B) deste local de convergência de canais de drenagem caracteriza a área mais vulnerável da Bacia Hidrográfica do Rio Machado aos processos hidrológicos.
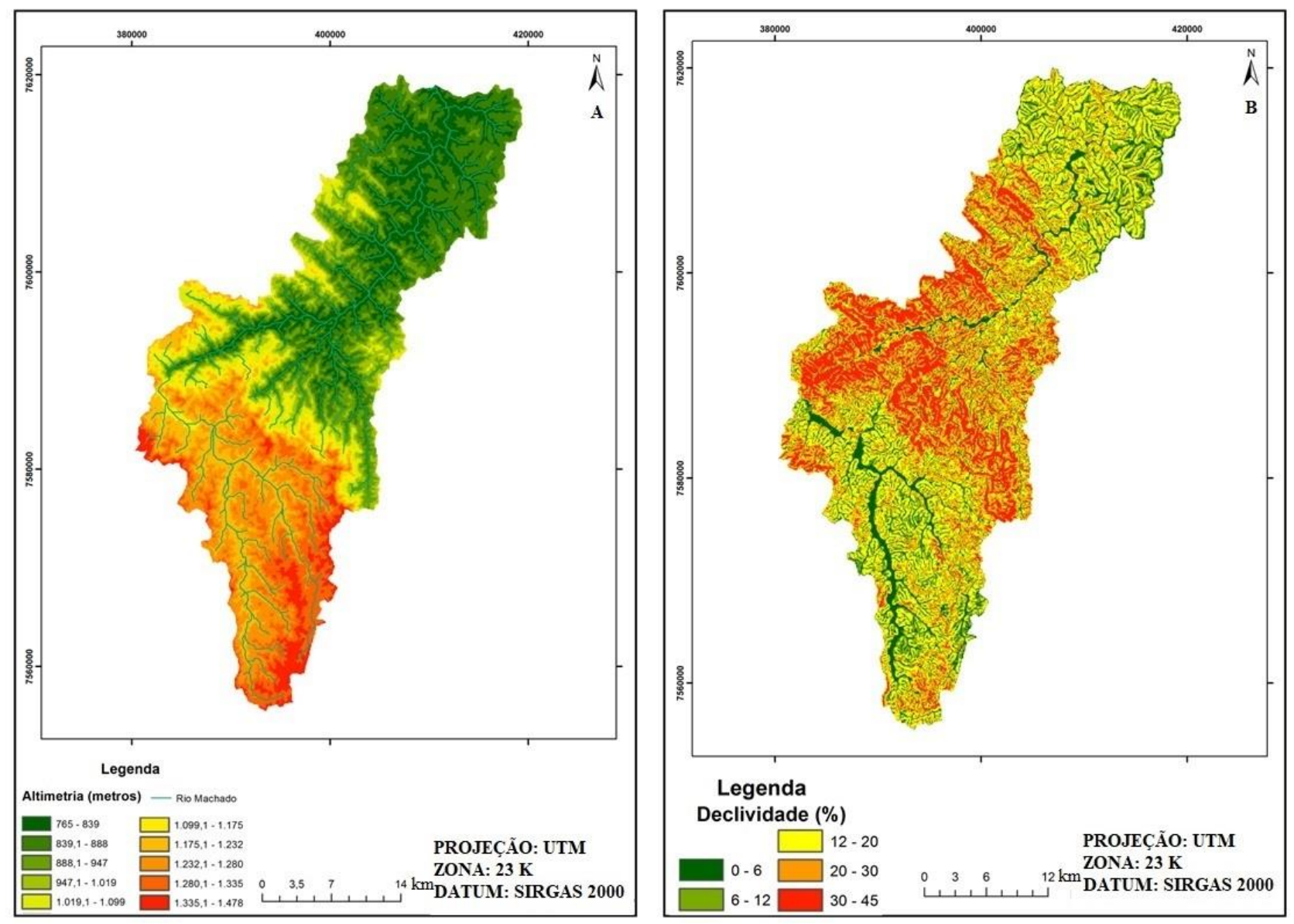

Figura 3 - Mapa Altimétrico (A) e Mapa de Declividade (B) da Bacia Hidrográfica do Rio machado. Fonte - Organização dos autores.

O Semivariograma (Figura 4), produzido no ArcGIS 10.5, permite ao usuário examinar a autocorrelação espacial entre os pontos amostrais medidos (ESRI, 2015). É presumido que amostras mais próximas possuem valores mais parecidos. Cada ponto vermelho no semivariograma representa um par de localizações. Neste caso, algumas correlações ficaram muito espaçadas, sendo necessário ajustar a ferramenta de pesquisa da krigagem para obtenção de resultados mais realistas. Outra observação é o fato de ocorrer algumas distorções nas bordas do modelo krigado. Isto devido à falta de amostragem nos divisores de águas. 


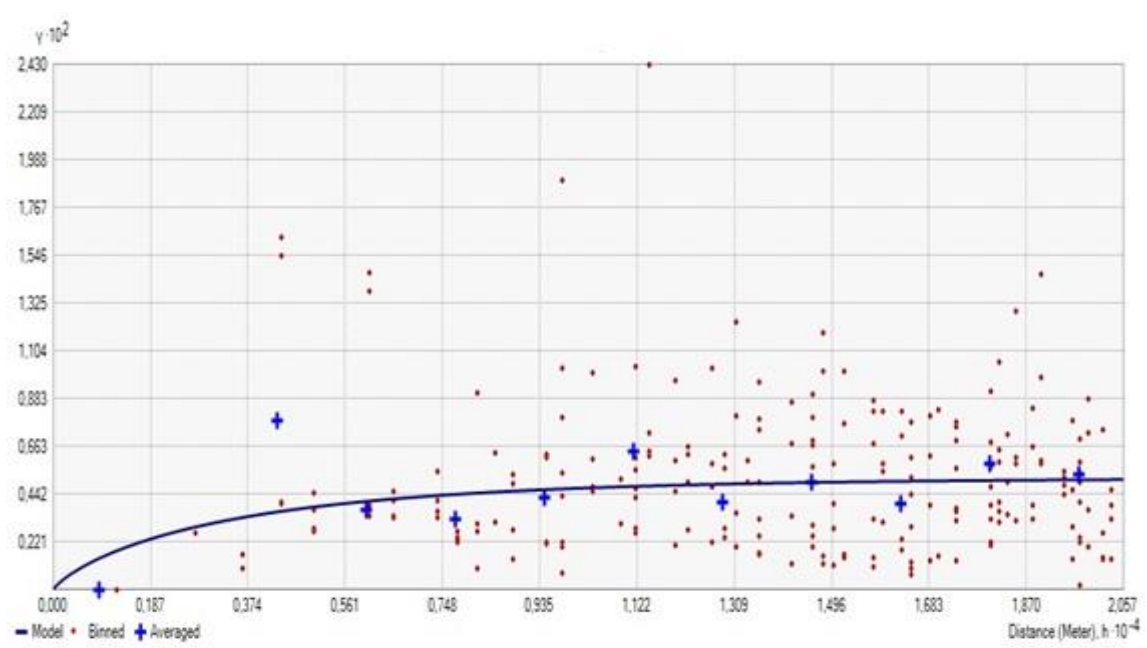

Figura 4 - Função variograma: indicativo da variabilidade dos pares amostrados. Fonte - Organização dos autores.

O Semivariograma foi utilizado para avaliar a correlação espacial entre os pontos de amostragem e indicou uma dependência espacial direta entre a RDdRb e os recursos hídricos. Isso era esperado, pois se trata de um índice que trabalha o comportamento hidrológico da rede de drenagem. Logo, o índice tende a ser mais elevado.

No gráfico de Análise de Tendências, cada barra vertical representa a localização e o valor (altura) de cada ponto de dados. Os pontos são projetados sobre os planos perpendiculares um a norte-sul e o outro a leste-oeste. A linha de melhor ajuste é desenhada através dos pontos projetados, indicando a direção que o conjunto de dados tende no modelo. Caso as linhas fossem retas, o indicativo é de que não existe qualquer tendência no conjunto de dados (Figura 4A).

Neste caso, foi avaliada a forte tendência dos dados correlacionados no sentido norte-sul, seguindo o curso do Rio Machado. Outra tendência avaliada é o fato de que valores elevados estão intimamente ligados a áreas bem drenadas e/ou com encontro de canais de drenagem (PEREIRA 20013). Era o esperado, por se tratar de um índice hidrológico, quanto maior a concentração de águas, maior a RDdRb e, consequentemente, maior risco a enchentes e inundações. Essas informações demonstram que a RDdRb sendo calculada em várias amostras ao longo da bacia e interpoladas estatisticamente, pode contribuir para o melhor planejamento estratégico de bacias hidrográficas em larga escala (Figura 5A).

A figura 5B ilustra o Gráfico de Distribuição Normal dos Dados. Esta ferramenta serve para validar a amostragem realizada do RDdRb. Quanto mais próximo os valores estiverem da reta normal mais coerênte foi amostragem (PEREIRA, 2013). É possível notar que alguns valores fogem um pouco da reta (Figura 5B). Este fato indica que ocorreram alguns erros de previsão, que representam 18\% dos erros associados do Modelo Krigado. Como os dados não apresentaram anormalidade acentuada, não foi aplicado nenhuma transformação matemática dos dados, conforme indica o manual do ArcGIS 10.5. (ESRI, 2015). Desta forma, os dados que foram krigados tiveram 
entrada no aplicativo Geostatistical Analysis sem sofrerem qualquer transformação (YAMAMOTO; LANDIN, 2013).
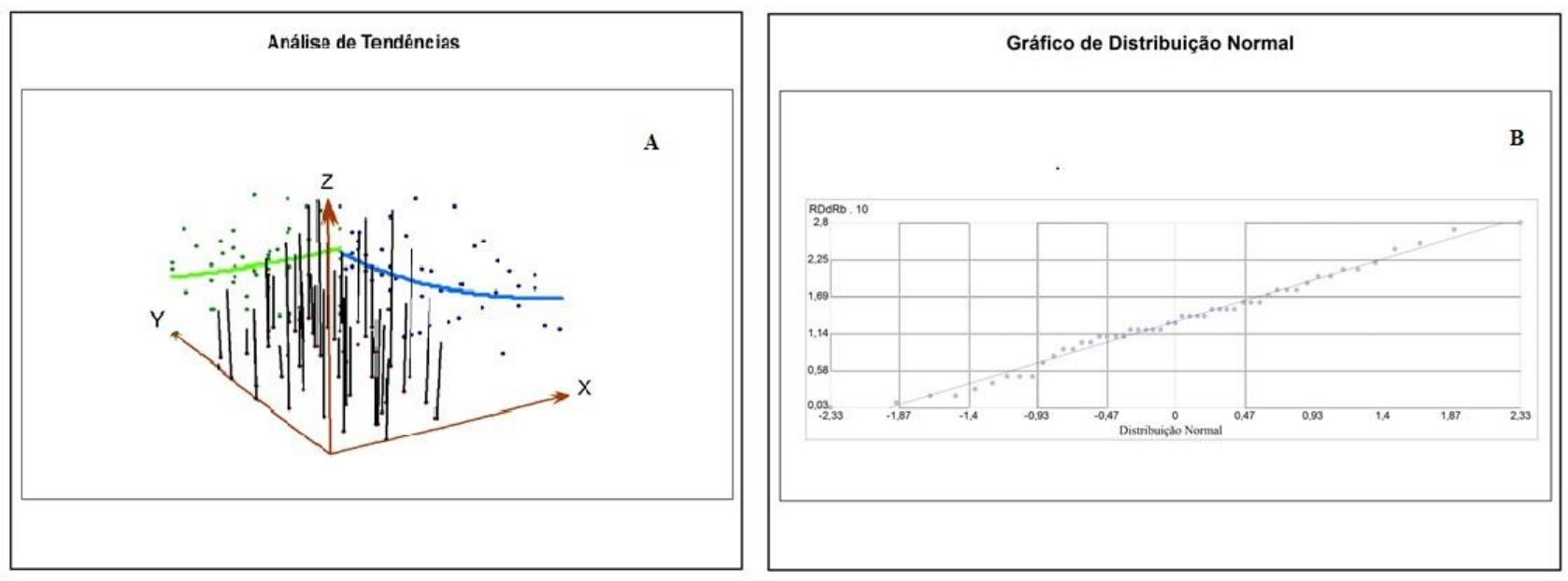

Figura 5 - Análise de Tendências (A) e Gráfico de Distribuição Normal.

Fonte - Organização dos autores.

Ocorreram alguns erros de estimativas, esperados por se tratar de uma metodologia estatística. Como a estatística trabalha com amostras de uma população, erros de estimativa são normais quando não ocorrem em excesso. O Índice de Compacidade é uma ferramenta utilizada para validar os dados do modelo krigado, é realizada automaticamente no aplicativo Geostatistical Analysis no ArcGIS 10.5 momentos antes de finalizar os procedimentos para elaboração da Krigagem Ordinária (ESRI, 2015). Variando de 0 à 1 o Indice de Compacidade para este modelo alcançou valor de 0,820 , com $82 \%$ de representação real do fenômeno abordado (PEREREIRA, 2013). O Índice de Compacidade é indispensável para compreender a RDdRb, pois é indicativo da veracidade produzida na pesquisa (LI et al., 2018).

\section{CONCLUSÃO}

A partir de ferramentas Geoestatísticas do ArcGIS 10.5 foi possível mensurar com maior detalhe, ainda que com poucas incertezas o comportamento da Relação da Densidade de Drenagem com o Índice de Bifurcação.

A distribuição da Relação da Densidade de Drenagem com o Índice de Bifurcação por meio da krigagem ordinária possibilitou localizar as áreas naturalmente vulneráveis a sofrerem com enchentes e inundações.

A aplicação da Krigagem ordinária auxiliou na modelagem espacial da Relação da Densidade de Drenagem com o Índice de Bifurcação, que pelo Índice de Compacidade mensurou a espacialização do índice com $82 \%$ de certeza sobre as informações disponibilizadas na pesquisa. 
A distribuição da Relação da Densidade de Drenagem com o Índice de Bifurcação demonstrou que o Município de Poço Fundo está localizado em um local naturalmente vulnerável a enchentes e inundações.

\section{REFERÊNCIAS}

ALMEIDA, R. A.; ROSA, D. R. Q.; FERREIRA, R. G.; DELAZARI, F. T.; ALMEIRA, I. A. Análise morfométrica de uma sub-bacia do rio Piracicaba (MG) utilizando sistemas de informação geográfica. Revista Engenharia na Agricultura, Viçosa, v. 25, n. 04, p. 372-380, 2017.

ALTIN, T. B.; ALTIN, B. N. Development and Morphometry of Drainage Network in Volcanic Terrain, Central Anatolia, Turkey. Geomorphology, Holanda, v. 125, n. 2, p. 486-503, 2010.

BHAGWAT, T. N.; SHERTTY, A.; HEGDE, V. S. Spatial Variation in Drainage Characteristics and Geomorphic instantaneous unit hydrograph (GIUH); implications for watershed management A Case Study of the Varada River Basin, Northern Karnataka. Catena, Holanda, v. 1, n. 87, p. 52$59,2011$.

CHRISTOFOLETTI, A. Modelagem de Sistemas Ambientais. 1. ed. São Paulo: Edgar Blucher Ltda, 1999. 236p.

DEMOULIN, A. Basin and River Profile Morphometry: A New Index With a High Potent for Relative Dating of Tectonic Uplift. Geomorphology, Holanda, v. 6, n. 1, p. 97-107, 2010.

ESRI, Enviromental Systems Research Institute - Inc. ARCGIS Professional GIS for the desketop version 10.5. Redlands, 2015. Disponível em: https://www.img.com.br/pt-br/ArcGIS/. Acesso em: 10 abr. 2019.

GONÇALVES SANTOS, T.; VENTORINI, S. E. Mapeamento de áreas suscetíveis: aos desastres humanos de natureza na bacia do córrego do lenheiro, Minas Gerais, Brasil. Revista Geográfica Venezolana, Caracas, v. 59, n. 1, 2018.

KESHTEGAR, B.; MERT, C.; KISI, Q. Comparison of four heuristic regression techiques in solar radiation modeling: Kriging method vs RSM, MARS and M5 model tree. Renewable and Sustainable Energy Reviews, Holanda, v. 81, n. 1, p. 330-341, 2017.

KIRAN KUMAR, K. M.; GOVINDAIAH, S.; NAGABHUSHAN, P. Morphometric Analysis of the Tumkur-Gubbi Watershedof Shimsha River Basin, Karnataka, India, by using Remote Sensing and GIS Techniques. International Journal of Creative Research Thoughts, Visakhapatnam, v. 6, n. 1, p.1628-1640, 2018.

KUNTAMALLA, S. G. S.; NALLA, M.; SAXENA, P. R. Drainage Basin Analysis through GIS: A Case study of Lakhnapur Reservoir Wathersed in Rangareddy District, Telangana State, India. International Journal of Engineering, Science and Mathmatics, Jagadhri, v. 7, n. 3, p. 09-17, 2018.

LI, Y.; ZHANG, Q.; WU, Y.; WANG, S. A sequential Kriging method assisted by trust region strategy for proxy cache size optimization of the streaming media vídeo data due to fragmente popularitu distribution. Multimedia Tools and Applications, Zurique, v. 1, n. 1, p. 1-20, 2018. 
LIMA, H. C.; DORANTI, C.; CHRISTIAN, H.; RIBEIRO, M. C. S.; RIBEIRO, L. F. B. Análise Morfométrica da Rede de Drenagem da Baciado Rio Machado - MG. Sociedade e Natureza, Uberlândia, v. 22, n. 1, p. 23-34, 2010.

MEDHI, B.; CHAKRAVARTTY, M.; PATGIRI, A. D. Infering Hydrological Characteristics of Gabharu River Basin, North-East índia, Based on the Application of Some Important Morphometric Parameters. Global Journal for Research Analysis, Londres, v. 6, n. 3, p. 10-12, 2017.

OLIVEIRA, I. M. S.; SILVEIRA, E. M. O.; PAIVA, L.; JÚNIR, F. W. A.; MELLO, J. M. Remote Sensing and Geostatistics Applied to Post-stratification of Eucalyptus Stands. Floresta e Ambiente, Rio de Janeiro, v. 25, n. 3, p. 1-11, 2018.

PUROHIT, K.; PARMAR, M. K. Morphometric Analysis and Correlation between Morphometric Parameters with Mean Basin Altitude and Slope: A case study of Alaknanda Basin, Uttarakhand, India. Global Journal for Research Analysis, Gujarat, v. 6, n. 7, p. 27-30, 2017.

REKHA, V. B.; GEORGE, A.V.; RITA, M. Mophometric Analysis and Micro-watershed Preioritization of Peruvanthanam Sub-watershed, the Manimala River Basin, Kerala, South India. Environmental Research, Engineering and Management, Lithuania, v. 3, n. 57, p. 6-14, 2011.

SALIH, S. A.; ULAIWI, J. H.; AL-TARIF, A. M.; AL-JUBOURY, A. I. Morphometric, Hidrogeologic and Hydrochemical Analyses of Solar Saltwork Pond Region, In Meha Area Northwest Sharqat city. Journal of Geographic Information System, Londres, v. 1, n. 4, p. 86-95. 2012.

SANTOS, C. A.; SOBREIRA, F. G. Análise morfométrica como subsídio ao zoneamento territorial: o caso das bacias do Córrego Carioca, Córrego do Bação e Ribeirão Carioca na região do Alto Rio das Velhas-MG. Revista Escola de Minas, Ouro Preto, v. 61, n. 1, p. 75-83, 2008.

SANTOS, L.; BACCARO, C. A. D. Caracterização Geomorfológica da Bacia do Rio Tijuco. Caminhos de Geografia, Uberlândia, v. 11, n. 1, p. 1-21, 2004.

SAUD, M. A. Morphometric Analysis of Wadi Aurnah Drainage System, Western Arabian Peninsula. 3. ed. Sharjah: Editora Benthan Open - The Open Hydrology Journal, 2009, 10p.

SOTCHAVA, V. B. O Estudo de Geossistemas: Métodos em Questão. 16. ed. São Paulo: IG-USP, 1977. 52p.

SUGUIU, K. Geologia Sedimentar. 1. ed. São Paulo: Edgar Blucher, 2003. 400p.

TAOFIK, O. K.; INNOCENT, B.; CHRISTOPHER, N.; JIDAUNA, G. G.; JAMES, A. S. A Comparative Analysis of Drainage Morphometry on Hydrologic Characteristics of Kereke and Ukoghor Basins on Flood Vulnerability in Makurdi Town, Nigeria. Journal Hydrology, Holanda, v. 5, n. 3, p. 32-40, 2017.

TRICART, J. A. Geomorfologia nos Estudos Integrados de Ordenação do Meio Natural. Boletim Geográfico, Rio de Janeiro, v. 34, n. 251, p. 15-42, 1976.

VALERIANO, M. M.; KUPLICH, T. M.; STORINO, M.; AMARAL, B. D.; MENDES JR, J. N.; LIMA, D. J. Modeling small watersheds in Brazilian Amazonia with shuttle radar topographic mission-90 m data. Computers \& Geosciences, Holanda, v. 32, n. 8, p. 1169-1181, 2006. 
VITTE, A. C. O Desenvolvimento do Conceito de Paisagem e a sua Inserção na Geografia. Revista de Geografia, Recife, v. 6, n. 11, p. 71-78, 2007.

YAMAMOTO, J. K.; LANDIM, P. M. B. Geoestatística: Conceitos e Aplicações. 2. ed. São Paulo: Oficina de Textos, 2013. 214p.

Trabalho enviado em 25/05/2019

Trabalho aceito em 25/06/2019 